\title{
Expectation confirmation: An examination of three competing models
}

\author{
Susan A. Brown ${ }^{\text {a }}$, Viswanath Venkatesh ${ }^{\text {b,* }}$, Jason Kuruzovich ${ }^{\mathrm{c}}$, Anne P. Massey ${ }^{\mathrm{d}}$ \\ ${ }^{a}$ Eller College of Management, $430 \mathrm{~W}$ McClelland Hall, University of Arizona Tucson, AZ 85721, USA \\ ${ }^{\mathrm{b}}$ Walton College of Business, University of Arkansas, 228 Business Building, Fayetteville, AR 72701, USA \\ ${ }^{\mathrm{c}}$ The Lally School of Management and Technology, Rensselaer Polytechnic Institute, 110 8th Street, Troy, NY 12180, USA \\ ${ }^{\mathrm{d}}$ Kelley School of Business, Indiana University, 1309 E. 10 th Street BU560 Bloomington, IN 47408, USA
}

Received 4 November 2002

Available online 22 October 2007

Accepted by Jeffrey Edwards

\begin{abstract}
We discuss three theoretical models from met expectations research in the fields of organizational behavior and consumer psychology. Based on the fundamental arguments in the models, we term these models: disconfirmation, ideal point, and experiences only. We present three-dimensional graphical and analytical representations of the models, with satisfaction being a function of expectations and experiences. We tested the models in the context of a new information system implementation in an organization, with expectations, experiences, and system satisfaction measured for both ease of use and usefulness, the focal constructs of the Technology Acceptance Model (TAM). We found that an experiences only model in which expectations had no measurable effect best explained the data for ease of use. The results for usefulness indicated a modified version of the experiences only model in which the positive effect of experiences becomes slightly stronger-i.e., more positive - as expectations increase.
\end{abstract}

(C) 2006 Elsevier Inc. All rights reserved.

Keywords: Expectation confirmation; Technology acceptance model; Polynomial modeling

Understanding the relationship among a priori expectations, a posteriori evaluations, and subsequent satisfaction-a stream of research referred to as met expectations - is an important issue for researchers and practitioners in a variety of domains. Porter and Steers (1973) defined met expectations in the context of employee jobs as the discrepancy between what one expects to experience and what one actually experiences on the job. Over the years, met expectations have been employed to predict several outcomes in different fields of research. For example, satisfaction is an important outcome that has been studied in a number of domains,

\footnotetext{
* Corresponding author. Fax: +1 4795753689.

E-mail addresses: vvenkatesh@walton.uark.edu, vvenkatesh@ vvenkatesh.us (V. Venkatesh).
}

including organizational behavior (e.g., Greenhaus, Seidel, \& Marinis, 1983), consumer psychology (e.g., Cadotte, Woodruff, \& Jenkins, 1987; Kopalle \& Lehmann, 2001), and information systems (e.g., Ginzberg, 1981; Szajna \& Scamell, 1993). In the organizational behavior literature, the degree to which job-related expectations are met has been positively associated with various outcomes, such as organizational commitment (Tannebaum, Mathieu, Salas, \& Cannon-Bowers, 1991; Wanous, Poland, Premack, \& Davis, 1992), job performance (Wanous et al., 1992), motivation (Tannebaum et al., 1991), and job satisfaction (Greenhaus et al., 1983). Related to this, unmet expectations have been negatively associated with newcomer's adjustment (Van Maanen, 1975; Wanous, 1980), and positively associated with absenteeism (Porter \& Steers, 1973), 
intentions to quit (Wanous et al., 1992), and turnover (Porter \& Steers, 1973; Wanous et al., 1992).

While the specific expectations, experiences, and outcomes studied are tied to the domain of investigation, common domain-independent theoretical models explaining how expectations and experiences combine to influence outcomes have emerged. The way in which expectations and experiences combine to influence outcomes in these domain-independent models is fairly complex. Although most models of met expectations suggest that initial expectations are the basis on which subsequent judgments are formed, the theoretical viewpoints differ in terms of how deviations from expectations-positive or negative, large or small - influence outcomes. Our review revealed a number of different models of expectation confirmation from which we chose three for discussion and empirical testing. The models were selected based on their applicability to the specific study, namely they focused on predicting satisfaction, the dependent variable of interest in the current study. The first two models that we identified focused on the combined effects of expectations and experiences in predicting satisfaction. Based on the theoretical exposition of the models, we term them: disconfirmation and ideal point models (see Anderson, 1973; see also Kopalle \& Lehmann, 2001; Szajna \& Scamell, 1993). In addition, there is a third, simpler model that uses experiences only as a predictor-this model serves as a baseline to benchmark the predictive validity of two more complex models (see Hom, Griffeth, Palich, \& Bracker, 1999; Irving \& Meyer, 1994).

Beyond the competing theoretical models, prior met expectations research has used methods and analytical techniques that make it difficult to understand whether the models are supported. Some studies have used linear models only (e.g., Churchill \& Surprenant, 1982; McElroy, Morrow, \& Mullen, 1996; Szajna \& Scamell, 1993), some have used difference scores approaches (see Edwards, 1994; Edwards \& Harrison, 1993; Edwards \& Parry, 1993 for a detailed discussion), and some have used direct measures of confirmation rather than measures of expectations and experiences separately (e.g., Bhattacherjee, 2001; Lee \& Mowday, 1987; Oliver, 1977; Saks, 1994; Suszko \& Breaugh, 1986). There has been an increasing awareness of and emphasis on the limitations of linear models, difference scores approaches, and the direct measurement of expectation confirmation (e.g., Edwards, 1995, 1996; Edwards \& Rothbard, 1999; Irving \& Meyer, 1995). In addition, Irving and Meyer (1994) specifically highlighted the problems of using difference scores in met expectations models, demonstrating the minimal impact of difference scores after controlling for experiences. As a result of these deficiencies, there is a need to reexamine the validity of previous theoretical models of met expectations using methodologies and analytical approaches that do not suffer from the limitations of past research.
This paper contributes to the literature by remedying the methodological and analytical limitations of prior research by representing the theoretical models of met expectations as three-dimensional response surfaces, specifying the analytical representations of these response surfaces, and testing the theoretical models using confirmatory polynomial regression procedures (Edwards, 2001; Edwards \& Parry, 1993). Therefore, relative to prior empirical tests of these models, this work presents a more in-depth examination of the models. We conduct an empirical test of the three models using data gathered in the setting of an organizational information system implementation, a critical area for gaining and sustaining competitive advantage in today's business world. We employ satisfaction, one of the key metrics of information system success (DeLone \& McLean, 1992, 2003; Seddon, 1997), as the dependent variable. A large body of literature in information systems has been dedicated to understanding information system satisfaction (e.g., Bailey \& Pearson, 1983; Devaraj, Fan, \& Kohli, 2002; Ginzberg, 1981; Ives, Olson, \& Baroudi, 1983; Melone, 1990), a key prerequisite for reaping benefits such as enhanced job performance and job satisfaction (DeLone \& McLean, 1992, 2003). Information systems are an important part of employee jobs and there is significant evidence to suggest that when employees are satisfied with aspects of their job, they are less likely to engage in counterproductive behaviors (see Lau, Au, \& Ho, 2003), perform better (Judge, Thoresen, Bono, \& Patton, 2001), and perform more desirable actions in the work place (Harrison, Newman, \& Roth, 2006). In addition, some have argued that organizational implementation of information systems be viewed as a process of change management (e.g., Markus \& Benjamin, 1997), suggesting that the results of this work could have broader implications for organizational change. Thus, understanding factors influencing information systems satisfaction has important implications for organizations. Finally, as technology has become a vehicle for conducting commerce, especially on the Internet, understanding how expectations and experiences influence satisfaction could also have implications for consumer behavior research (e.g., Devaraj et al., 2002; McKinney, Yoon, \& Zahedi, 2002).

\section{Theory}

In this section, we first review the theoretical arguments and findings related to the three models. We then discuss methodological and analytical issues related to much of the prior research on met expectations. This is followed by a discussion of the context of the study-i.e., information systems implementation. Finally, we use theoretical guidance to develop threedimensional response surfaces and analytical representations for the three models. The response surfaces 
illustrate graphically how experiences and expectations relate to satisfaction for each model and the analytical representations help us develop testable hypotheses for each model.

\section{Theoretical models of expectation confirmation}

\section{Disconfirmation}

The first model, labeled disconfirmation, is based in disconfirmation and contrast theories (Churchill \& Surprenant, 1982; Sherif \& Hovland, 1961), with studies in a variety of domains. The model suggests that satisfaction is influenced by the level of disconfirmation, or the degree to which expectations are unmet. Disconfirmation suggests that whenever experiences fall short of expectations, such experiences reduce satisfaction-i.e., a disappointment effect. When experiences exceed expectations, expectations exert a positive influence on satisfaction-i.e., a positive surprise effect. These effects are consistent with the met expectations hypothesis that suggests satisfaction is a function of the difference between experiences and expectations (e.g., Porter \& Steers, 1973; Wanous, 1992). In this view, high positive disconfirmation, or the degree to which expectations are exceeded, leads to greater satisfaction while high negative disconfirmation leads to lower satisfaction (Kopalle \& Lehmann, 2001; for a review, see Yi, 1990). Thus, a disconfirmation view offers management recommendations that expectations should be understated in order to maximize the expectation-outcome gap in the positive direction-i.e., the degree to which experiences exceed expectations.

Empirical support for a disconfirmation model can be found in realistic job previews (e.g., Phillips, 1998; Wanous, 1992) and the met expectations hypothesis (Porter \& Steers, 1973) research streams. Early research in this area suggested that unrealistically high expectations can result in low satisfaction (Kotter, 1973). The primary proposition of subsequent work in realistic job preview research is that when employees have realistic job previews - i.e., their expectations more closely align with the job conditions they will encounter - they are more likely to have their expectations met or exceeded and thus, will be more satisfied and less likely to leave their jobs (Dugoni \& Ilgen, 1981; Lee, Ashford, Walsh, \& Mowday, 1992; Wanous, 1992). Previous studies of newcomer adjustment have shown that job recruits typically have unreasonably high expectations (Wanous, 1980, 1992) that can lead to negative outcomes, such as dissatisfaction and ultimately, turnover (Lee et al., 1992). When these unrealistically high expectations meet reality, they serve as a sort of reality shock for newcomers (Dugoni \& Ilgen, 1981; Major, Kozlowski, Chao, \& Gardner, 1995). Realistic job preview research proposes that lower expectations are more easily met and exceeded (Premack \& Wanous, 1985). Further, they should reduce the shock and the resulting dissatisfaction that newcomers experience (Wanous, 1992). Overall, lowered expectations have a positive influence on job-related outcomes, such as satisfaction (Buckley, Fedor, Veres, Wiese, \& Carraher, 1998; Lee et al., 1992). In a study of affective reactions to lottery winnings, Mellers, Schwartz, Ho, and Ritov (1997) found that individuals were more satisfied with a positive outcome when a negative outcome was expected and more dissatisfied with a negative outcome when a positive outcome was expected. Finally, in a study of information systems implementation, Staples, Wong, and Seddon (2002) found that unrealistically high expectations were associated with lowered information system satisfaction.

\section{Ideal point}

A second model, labeled ideal point that builds on the idea of congruence, proposes that any difference between expectations and experiences, regardless of the direction, will result in a lowered evaluation (e.g., Oliver, 1976; Olson \& Dover, 1979). In contrast to the disconfirmation model, the ideal point model anticipates negative outcomes when expectations are both not attained and when they are exceeded. In this case, expectations serve as an anchor such that there is an ideal point of experience in which the difference between the expectation and the experience is minimized. Oliver (1976) argued that reduced satisfaction due to exceeded expectations is most likely to occur when the expectation object is particularly important to the individual, as is likely the case with an information system due to the necessity of system use in performing one's job. In their meta-analysis of met expectations research, Wanous et al. (1992) posed a question regarding the relative impact of over- versus under-fulfillment of expectations. They suggested that future research pay attention not only to whether or not expectations were met, but also to the direction of the difference.

For additional clarification, we turn to the psychological contract literature that suggests expectations, which are formed based on perceived promises by the employer, are the basis for the psychological contract (Robinson, 1996). When experiences disconfirm the expectations associated with the psychological contract, the violations have a negative impact on satisfaction (Lambert, Edwards, \& Cable, 2003; Sutton \& Griffin, 2004; Turnley \& Feldman, 2000). Moreover, employees who receive more than what they expected would be dissatisfied because excess levels would interfere with need fulfillment (Lambert et al., 2003). In reconciling the conflicting findings in expectations research, Ginzberg (1981) argued that the most consistent explanation for why people are satisfied with an information system is that their expectations are realistic - neither too high nor too low, Ginzberg's research demonstrated that users who held realistic expectations were more satisfied 
with the resulting information system than were users with unrealistic expectations. Likewise, Bhattacherjee (2001) argued that satisfaction is a function of the degree to which expectations are confirmed. His empirical results support this view. Finally, Staples et al. (2002) found that when the difference between expectations and experiences is minimized, users will be most satisfied with the information system.

\section{Experiences only}

One other model of interest in understanding the relationship among expectations, evaluations, and an outcome (e.g., satisfaction) is experiences only. An experiences only view of the role of expectations anchors subsequent evaluations on actual experiences and renders expectations inconsequential to the outcome evaluations. It could be argued that there is a recency effect (Tversky \& Kahneman, 1974) that causes the experiential evaluations to be most salient and thus, most influential in determining an outcome assessment. The experiences only model has been supported by Hom et al. (1999) who examined experiences in light of a number of outcomes including satisfaction. Likewise, Irving and Meyer (1994) found that job satisfaction was driven by experiences rather than expectations.

\section{Methodological and analytical shortcomings of prior studies}

There are three key shortcomings associated with prior expectations research: (1) the predominant use of linear models and associated analytical techniques; (2) the use of difference scores for analyses; and (3) the direct measurement of confirmation rather than the measurement of expectations and experiences separately. Below, we elaborate on each of these limitations.

Even though the theoretical propositions predict nonlinear effects, much of the empirical support in prior work testing the complex theoretical propositions of the models has used linear models/equations and associated analyses (e.g., Churchill \& Surprenant, 1982; McElroy et al., 1996; Szajna \& Scamell, 1993). In expectations research, the assumption of linearity implies similar effects of expectations and experiences on an outcome. However, some research has highlighted that the assumption of linearity may be masking the true relationships among the variables (e.g., Edwards \& Rothbard, 1999; Irving \& Meyer, 1994; Staples et al., 2002). In fact, linear models would simply not allow a test of the complex propositions of the disconfirmation and ideal point models, thus constraining our ability to accurately test the models. Edwards (2001) argued that higher-order terms in curvilinear models may explain substantial variance over and above linear models.

Difference scores, as a means of assessing the impact of expectation confirmation on outcomes, have been used in a variety of studies (e.g., Ilgen, 1971; Patterson, 1993; Staples et al., 2002; Venkatraman \& Prescott, 1990; Weaver \& Brickman, 1974). However, research has suggested difference scores have significant statistical flaws (Edwards, 1994, 2002; Edwards \& Harrison, 1993; Peter, Churchill, \& Brown, 1993; Pitt, Watson, \& Kavan, 1997; Prakash, 1984). In expectations research, the use of difference scores implies that expectations and experiences have equal and opposite effects on the outcome (Hom et al., 1999). While this is consistent, in part, with a disconfirmation view of expectations, it is not consistent with the other two models. Hom et al. (1999) demonstrated the impact of attending to this shortcoming and the resulting difference in outcomes: the use of difference scores was associated with an overstatement of the mediating role of met expectations. In essence, the use of difference scores imposes a constraint such that it will likely only support a disconfirmation model.

Another measurement issue has been the use of direct measures of disconfirmation (e.g., Bhattacherjee, 2001; Bhattacherjee \& Premkumar, 2004; Lee \& Mowday, 1987; Oliver, 1977; Saks, 1994; Suszko \& Breaugh, 1986) rather than measurement of expectations and experiences separately. Research taking this approach measures the degree to which a participant's expectations were met. This does not allow for an understanding of the relative impact of expectations and experiences on satisfaction (Irving \& Meyer, 1994, 1995). Further, Irving and Meyer $(1994,1995)$ reported that responses to met expectations questions appear to be disproportionately influenced by current experiences. This potential for undue influence is clearly consistent with the predictions of cognitive dissonance theory that suggests that as individuals attempt to limit dissonance between expectations and experiences, they underreport differences in order to remain cognitively consistent (Festinger, 1962). Likewise, the hindsight bias suggests that individuals engage in revisionist history in order to create cognitive consistency (Christensen-Szalanski \& Willham, 1991; Hawkins \& Hastie, 1990). Thus, it is highly likely that when individuals who have experience with a particular behavior are asked to rate the degree to which their expectations were confirmed, they will overstate the agreement between expectations and experiences. This would influence the results in such a way that it would be difficult to know, for example, if the evaluations of the experiences were assimilated toward expectations or if expectations were actually revised post hoc to be consistent with experiences.

\section{Domain of study: information systems implementation}

A key step in expectations research is to examine the important focal constructs - expectations, experiences, and outcomes (Porter \& Steers, 1973; Wanous et al., 
1992) - in the specific domain of study. The domain in the current work is an information systems implementation. In this context, information system satisfaction is the dependent variable. Information system implementation is a critical area for gaining and sustaining competitive advantage in today's business world. While estimates of information technology investment in organizations indicate that they represent about $50 \%$ of all new capital investment, the success rate of these implementations is well below 50\% (see Davis \& Venkatesh, 2004).

A review of the information systems implementation literature revealed a few studies of the relationship between expectations about an information system and attitude formation (e.g., Lawrence \& Low, 1993; Yoon \& Guimaraes, 1995; Zmud, 1980). Researchers have also studied the impact of met expectations on information system satisfaction (e.g., Bhattacherjee, 2001; Bhattacherjee \& Premkumar, 2004; Ginzberg, 1981; Lyytinen, 1988; Staples et al., 2002; Szajna \& Scamell, 1993). Like expectations research in other domains, information systems research also suffers from the methodological and analytical limitations outlined earlier.

To select the relevant expectations and experiences to study, we reviewed the information systems literature and found that the technology acceptance model (TAM; Davis, 1989; Davis, Bagozzi, \& Warshaw, 1989) was the most widely used way to understand user reactions to new information systems (see Venkatesh, Morris, Davis, \& Davis, 2003). According to recent assessments, the two key papers introducing TAM (Davis, 1989; Davis et al., 1989) have been cited in excess of 400 times (see Venkatesh \& Davis, 2000). Our citation analysis found that there were over 1000 cites to those two papers. Thus, we chose to study the two key predictors of information system success suggested in TAM: ease of use, defined as the degree to which using a system is relatively free from effort; and usefulness, defined as the degree to which using the system enhances an individual's effectiveness (Davis et al., 1989). TAM has been repeatedly tested and extended, with results supporting the predictive validity of the model (e.g., Mathieson, 1991; Moon \& Kim, 2001; Taylor \& Todd, 1995; Venkatesh \& Davis, 2000). While technology acceptance research typically uses behavioral intention as the dependent variable, other research (Brown, Massey, Montoya-Weiss, \& Burkman, 2002) has suggested that system satisfaction, and not behavioral intention to use the system, is the appropriate dependent variable when the system in question is large scale, integrated, and its use is mandated in the organization. As noted earlier, system satisfaction is one of the key metrics of information system success (DeLone \& McLean, 1992, 2003; Seddon, 1997). In sum, we study expectations and experiences regarding ease of use and usefulness as predictors of information systems satisfaction.
Polynomial regression analysis and response surface methodology

Polynomial regression analysis and response surface methodology (e.g., Edwards, 2001; Edwards \& Parry, 1993) provide the right procedures to represent and test the theoretical propositions of the models while overcoming the limitations of much prior research. These analytical techniques have been used to examine a variety of phenomena, such as goal congruence (e.g., Kristof-Brown \& Stevens, 2001), person-environment fit (e.g., Edwards \& Harrison, 1993), person-organization fit (e.g., Van Vianen, 2000), personality similarity (e.g., Antonioni \& Park, 2001), and self-other agreement (e.g., Atwater, Ostroff, Yammarino, \& Fleenor, 1998; Johnson \& Ferstl, 1999). In each of these domains, the use of polynomial regression analysis and response surface methodology led to a more complete picture of the relationship among the congruence of independent variables and outcomes of organizational interest, thus providing a deeper and more accurate understanding of underlying phenomena. Because the three models of met expectations that we discussed were tested using methodologies and analytical techniques with significant limitations, it is almost impossible to know from prior research whether there was empirical support for the theoretical propositions of the different models. In this work, polynomial regression analysis and response surface methodology will provide a way to fully and accurately represent the complexities of the theoretical propositions in two of the three models-i.e., disconfirmation and ideal point.

Depending on the specific theoretical relationships, linear (Eq. 1) or quadratic (Eq. 2) forms of the unrestricted polynomial regression equations are used to represent the theoretical models and regression equations (Edwards \& Parry, 1993):

$Z=b_{0}+b_{1} X+b_{2} Y+e$.

$Z=b_{0}+b_{1} X+b_{2} Y+b_{3} X^{2}+b_{4} X Y+b_{5} X^{2}+e$.

\section{Analytical representation of the competing models}

We translated the tenets of the competing models of expectation confirmation into three-dimensional response surfaces. The response surfaces showing the relationship among experiences $(X)$, expectations $(Y)$, and satisfaction $(Z)^{1}$ for each of the models are shown in Fig. 1. In generating these models, the coefficients were derived analytically from the theoretical relationship between experiences and expectations. The patterns

\footnotetext{
${ }^{1}$ Throughout this discussion we will refer to experiences, expectations, and satisfaction using the axes on which each-i.e., $X, Y$, and $Z$-is plotted.
} 
A

\section{Disconfirmation}

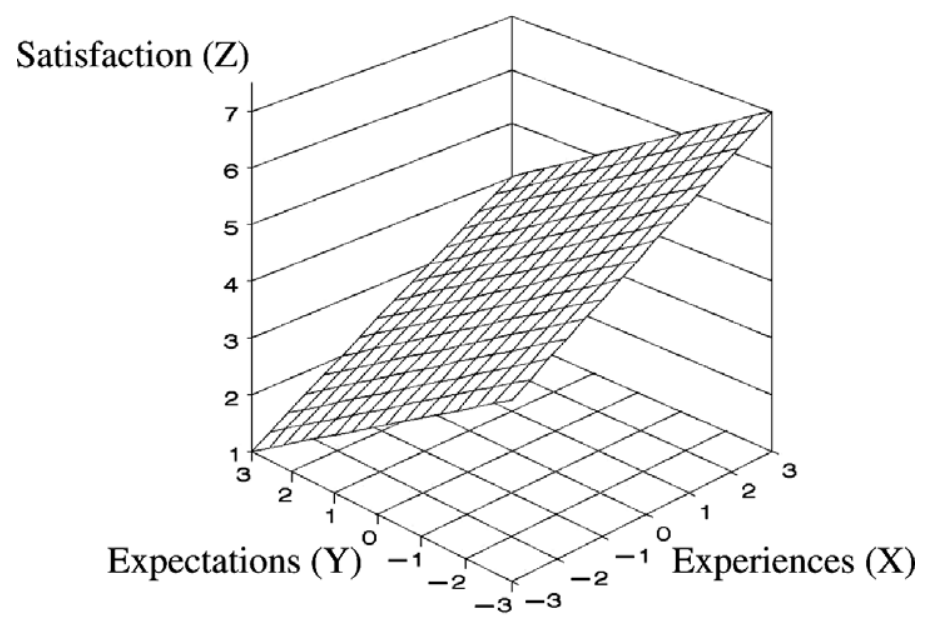

B

\section{Ideal Point}

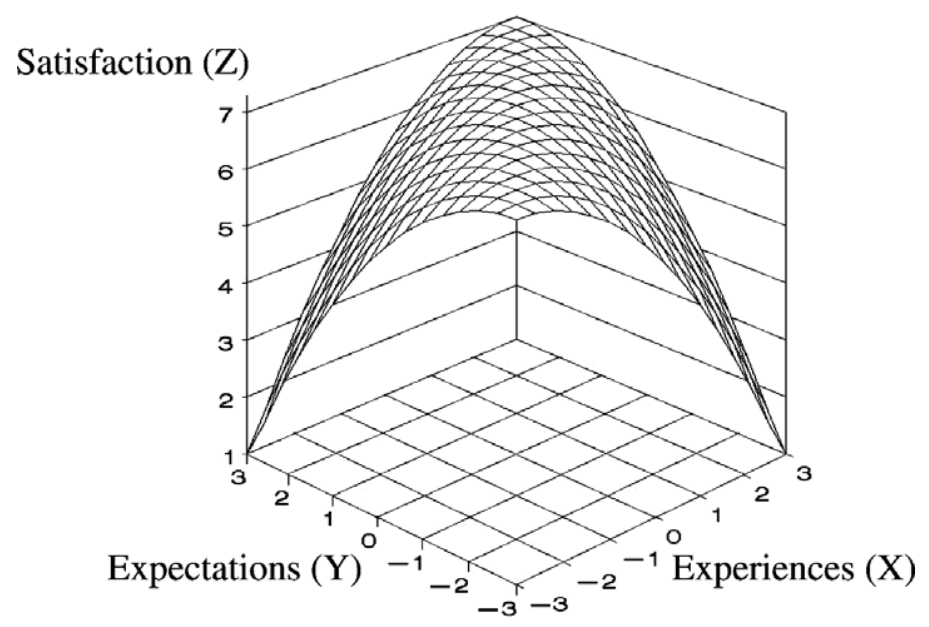

C

Experiences Only

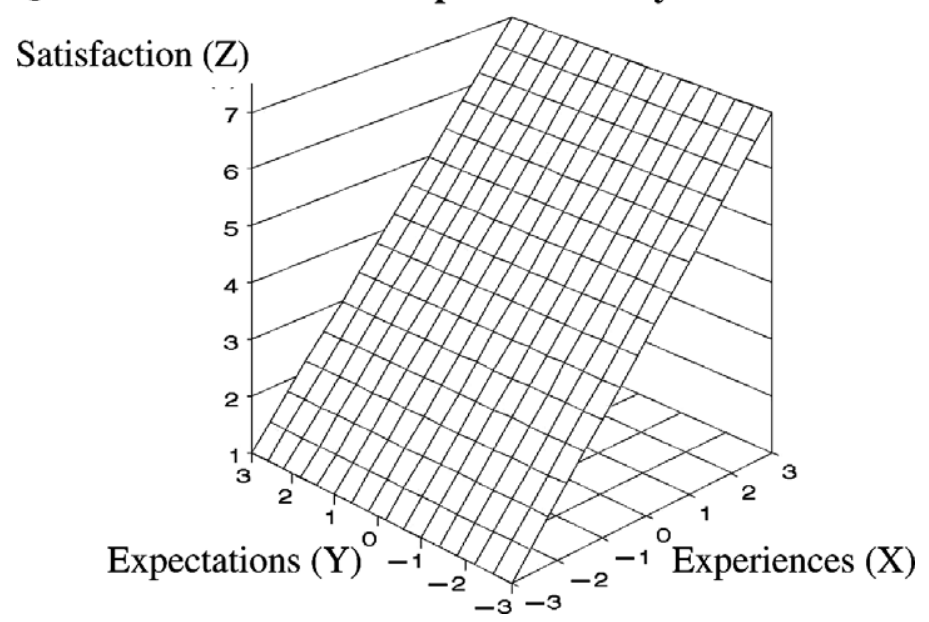

Fig. 1. (A-C) Response surface representations of theoretical models.

of coefficients for the hypothesized response surfaces are found in Table 1 .

In creating the response surfaces, we placed a specific emphasis on answering three questions. First, how does satisfaction change as experiences increase toward expectations? Second, how does satisfaction change as experiences exceed expectations? Third, is the level of satisfaction when experiences and expectations are low 
Table 1

Expected pattern of coefficients and associated constraints for existing models of expectation confirmation

\begin{tabular}{|c|c|c|c|c|c|c|}
\hline \multirow[t]{2}{*}{ Description } & \multicolumn{2}{|c|}{ Monotonic } & \multicolumn{3}{|c|}{ Quadratic } & \multirow[t]{2}{*}{ Other constraints } \\
\hline & $\begin{array}{l}X \\
\left(b_{1}\right) \\
\end{array}$ & $\begin{array}{c}Y \\
\left(b_{2}\right) \\
\end{array}$ & $\begin{array}{l}X^{2} \\
\left(b_{3}\right)\end{array}$ & $\begin{array}{l}X^{*} Y \\
\left(b_{4}\right)\end{array}$ & $\begin{array}{l}Y^{2} \\
\left(b_{5}\right)\end{array}$ & \\
\hline Experiences only & + & 0 & & & & \\
\hline Disconfirmation & + & - & & & & $b_{1}=-b_{2}$ \\
\hline Ideal point & 0 & 0 & - & + & - & $b_{1}=0, b_{2}=0 ; b_{3}=b_{5} ; b_{3}+b_{4}+b_{5}=0$ \\
\hline
\end{tabular}

Notes. $X$, experiences and $Y$, expectations. Other constraints relate specifically to the relative size of the unstandardized regression coefficients.

different from the level of satisfaction when experiences and expectations are high? In answering these questions, we emphasized the surface features along the disconfirmation axis, where $X=-Y$, and the confirmation axis, where $X=Y$. As it is difficult to directly interpret regression coefficients associated with response surfaces, the slopes along lines of interest - here, the confirmation and disconfirmation axes - provide a way to understand theoretical relationships (Edwards \& Parry, 1993). The use of the confirmation and disconfirmation axes is consistent with prior research that studied how supplies and values influence well being (Edwards, 1996; Edwards \& Cooper, 1990; Edwards \& Rothbard, 1999). In addition, we examined constraints regarding the relative magnitude of the coefficients to ensure that deviations from the hypothesized shape would be identified (see Edwards, 2001; Edwards \& Parry, 1993). For quadratic and second-order response surfaces, it is important to check for additional response surface features such as stationary points and principal axes. The stationary points help us in determining the absolute maximum or minimum for a surface. Identification of the principal axes is important for determining any lateral shift or rotation in the surface.

\section{Disconfirmation}

The shape of the response surface for the disconfirmation model varies primarily based on experiences (Churchill \& Surprenant, 1982; Sherif \& Hovland, 1961). Satisfaction increases as experiences increase toward expectations and continues to increase to its highest level as experiences exceed expectations. As higher levels of expectations can only increase the likelihood that expectations are negatively disconfirmed, increasing the levels of expectations reduces satisfaction. This results in a positive slope along the disconfirmation axis (i.e., $X=-Y$ ) where satisfaction is maximized when experiences are very high and expectations are very low. The level of satisfaction when both experiences and expectations are low is the same as the level of satisfaction when both experiences and expectations are high, as the disappointment or surprise effects of disconfirmation rely on the relative levels of expectations and experiences and not on their absolute levels. The resulting slope along the confirmation axis (i.e., $X=Y$ ) is equal to zero. Support for the disconfirmation model would suggest a positive coefficient for experiences $(X)$ and a negative coefficient for expectations $(Y)$, with the coefficients equal in magnitude but opposite in sign.

\section{Ideal point}

The response surface for the ideal point model suggests that satisfaction will be greatest when expectations are equal to experiences (Olson \& Dover, 1979). Satisfaction decreases symmetrically both as experiences exceed expectations and as experiences fall short of expectations. Further, satisfaction decreases more steeply as the overall magnitude of the difference between experiences and expectations increases. This results in an inverted U-shaped curve along the disconfirmation axis. When experiences and expectations are equal, satisfaction is maximized - i.e., the ideal points. Such high satisfaction is felt when experiences and expectations are both low and when they are both high. Like the disconfirmation model, this results in a slope that is equal to zero along the confirmation axis. Support for the ideal point model would suggest that the coefficient for experiences $(X)$ and expectations $(Y)$ are both equal to zero. Negative coefficients for $Y^{2}$ and $X^{2}$ that are equal in magnitude create the symmetric concave surface such that satisfaction decreases both as experiences exceed and fall short of expectations. The positive coefficient for $X Y$ and the additional constraint that the coefficients for $X^{2}, X Y$, and $Y^{2}$ sum to zero enables satisfaction to be maximized along the length of the confirmation axis.

\section{Experiences only}

The experiences only model suggests that satisfaction is determined entirely by experiences. This results in a positive and linear slope along both the confirmation and disconfirmation axes, as satisfaction increases with increasing levels of experiences irrespective of levels of expectations. For the experiences only model, only the $X$ coefficient is positive and significant.

\section{Methods}

\section{Research setting and participants}

The setting for this study is a $\$ 5$ billion multi-bank holding company (BHC). BHC provides a range of 
financial services including commercial and retail banking, trust, brokerage, correspondent banking, and insurance. At the time of the study, BHC was pursuing a growth strategy that included acquiring smaller banks. In order to consolidate financials and facilitate reporting, BHC converted the acquired banks to a common banking system that is referred to as CBS in the rest of this paper. CBS was the target information system in this work.

Participants consisted of 986 employees from 17 affiliates undergoing implementation of CBS. Seven hundred forty-two complete, usable responses were received, resulting in an overall response rate of $75 \%$. The average age of respondents was 39.4 , with a standard deviation of 11.7. Respondents had been employed by their respective affiliates for an average of 10.6 years, with a standard deviation of 8.6. Eighty-six percent of respondents held the same positions before and after the conversion. Positions included executive/top management $(5 \%)$, middle management/supervisory $(18 \%)$, technical support and operations (11\%), administrative/clerical $(12 \%)$, teller/customer service representatives $(44 \%)$, lenders $(5 \%)$, and other roles such as marketing and collections (5\%). Information system implementations often involve changes to job responsibilities (e.g., Pinsonneault \& Kraemer, 1997; Pinsonneault \& Rivard, 1998). Job changes associated with an information system implementation have the potential for both positive and negative affective responses. These responses may lead to altered perceptions of the information system. In order to mitigate confounds associated with job changes, we limited our focus to the 648 individuals who were in the same job before and after the implementation. Regression analysis using a general linear model found that neither position nor affiliate had a significant influence on satisfaction when controlling for expectations and experiences.

\section{Design and procedure}

A manager at BHC distributed surveys to all employees of the 17 bank affiliates undergoing conversion from old, disparate systems to the new system-i.e., CBS. Letters from the researchers and the manager were included with the surveys. These letters explained the study, BHC's approval of the study, BHC's interest in the study, and our guarantee of confidentiality. To encourage participation, we included addressed, stamped envelopes and had all responses sent to the researchers rather than anyone in the organization.

Participants were asked to report their expectations about CBS at the time of its introduction. Initial information about the CBS was through organizational communications and announcements. Expectations formed via vicarious methods (e.g., watching others, hearing about something) tend to be higher and less stable than those formed via direct experience (Fazio \& Zanna, 1981). Bandura (1986) indicated that persuasion (i.e., hearing from others) is less effective in forming self-efficacy expectations than actual experiences are in forming self-efficacy. This suggests that some direct experience is needed to form meaningful expectations. Thus, we assessed expectations only after training on the system. Due to data being gathered from 17 different locations, the actual time of measurement of experiences varied due to practical constraints. Specifically, we gathered information related to experiences between four and six months after the implementation of CBS.

\section{Measures}

The scales for ease of use and usefulness were adapted from prior research (e.g., Davis et al., 1989; Venkatesh \& Davis, 2000). The items were appropriately worded to measure expectations (before the CBS implementation) and experiences (after the CBS implementation), respectively. Satisfaction has been measured in many different contexts in organizational behavior, information systems, and consumer psychology. The satisfaction scale we used was consistent with prior research (see Churchill \& Surprenant, 1982; Klein, 1999), including information systems satisfaction research (e.g., Davis, 1993; Karahanna, Straub, \& Chervany, 1999), and asked individuals about their feelings associated with the CBS.

The five constructs used in the analysis were ease of use (expected), ease of use (experienced), usefulness (expected), usefulness (experienced), and satisfaction. The scales for each of the five factors exhibited adequate reliability with Cronbach alpha values ranging from 0.84 to 0.93 . In addition, the five factors were modeled together using confirmatory factor analysis, which provides information about the convergence of the items on the factors and the discriminant validity of the factors (e.g., Anderson \& Gerbing, 1988). The confirmatory factor analysis showed adequate fit for the five factor solution: $\chi^{2}(90, N=648)=198.32, p<0.001 ; \chi^{2} / d f=2.20$; root-mean-square residual (RMSR) $=0.061$; comparative fit index $(\mathrm{CFI})=0.989$; incremental fit index $(\mathrm{IFI})=0.989$. The average standardized item loadings on each of the factors were: ease of use (expected) $=0.82$; ease of use $($ experience $)=0.75$; usefulness $($ expected $)=$ 0.90 ; usefulness (experience) $=0.90$; and satisfaction $=0.84$.

\section{Analysis}

Measures for expectations and experiences for both ease of use and usefulness were calculated by averaging the scale-centered (i.e., subtracted by the midpoint of the scale) item scores for ease of use and usefulness. Scalecentering reduces multicollinearity and allows a meaningful interpretation of the coefficients of the first-order 
terms (Aiken \& West, 1991; Edwards, 1994; Jaccard, Wan, \& Turrisi, 1990). Prior to conducting the regression analysis, we screened for outliers using leverage, Cook's D, and standardized residuals from quadratic regression equations (Belsley, Kuh, \& Welsch, 1980; Fox, 1991). We excluded cases per the criteria set in Bollen and Jackman (1990). This method was conservative and resulted in the elimination of 13 cases from the ease of use analysis and 7 from usefulness analysis.

Confirmatory polynomial regression analysis (Edwards, 2001; Edwards \& Parry, 1993) was used to test the models. The confirmatory analysis was conducted using the quadratic version of the unconstrained regression equation (Eq. 2) to generate the response surfaces for both ease of use and usefulness. Support for any individual model requires that: (1) the variance explained by the equation differs from zero; (2) the coefficients follow the appropriate pattern; (3) the constraints of the model are satisfied; and (4) the variance explained by the set of terms one order higher than those in the equation does not differ from zero (Edwards, 2001).

\section{Results}

Table 2 presents the descriptive statistics and correlations. Overall, correlations between ease of use and usefulness expectations and experiences were under 0.60 , with most correlations being about 0.40 . Correlations between experiences and satisfaction were higher than those between expectations and satisfaction. Correlations between usefulness and satisfaction were slightly higher than the correlations between ease of use and satisfaction for both expectations and experiences. The means for expectations were higher than the means for experiences. Also, the standard deviations in all cases were higher for experiences than for expectations.

Table 3 presents the unstandardized coefficients for the unconstrained quadratic equation, tests of higher-order models, and tests of model constraints. Fig. 2 presents the graphical plots of the ease of use and usefulness models. The equations yielded significant $R^{2}$ for both ease of
Table 3

Results from quadratic regressions of expectations and experiences on satisfaction with additional calculations

\begin{tabular}{|c|c|c|}
\hline & Ease of use ${ }^{a}$ & Usefulness $^{\mathrm{a}}$ \\
\hline \multicolumn{3}{|c|}{ Unconstrained quadratic equation } \\
\hline C & $4.769^{* * *}$ & $4.988^{* * *}$ \\
\hline$X$ & $0.478 * * *$ & $0.429 * * *$ \\
\hline$Y$ & $0.082^{\psi}$ & -0.012 \\
\hline$X^{2}$ & 0.012 & -0.006 \\
\hline$X Y$ & 0.015 & $0.039 *$ \\
\hline$Y^{2}$ & -0.002 & 0.004 \\
\hline$R^{2}$ & $0.417 * * *$ & $0.501 * * *$ \\
\hline \multicolumn{3}{|l|}{ Confirmatory tests } \\
\hline$F_{\mathrm{H}(\text { Cubic })}{ }^{\mathrm{b}}$ & 1.588 & 1.357 \\
\hline$F_{\mathrm{C}(\text { Disconfirmation })}{ }^{\mathrm{c}}$ & $102.23^{* * *}$ & $148.88^{* * *}$ \\
\hline$F_{\mathrm{C}(\text { Ideal point })^{\mathrm{c}}}$ & $93.96^{* * *}$ & $102.28 * * *$ \\
\hline
\end{tabular}

use $\left(R^{2}=0.417, F_{5,633}=90.274, p<0.001\right)$ and usefulness $\left(R^{2}=0.501, F_{5,631}=128.835, p<0.001\right)$, but the observed pattern of coefficients did not exactly match that of any of the predicted models. The ease of use model yielded a positive coefficient for $b_{1}(p<0.001)$ while the usefulness model yielded positive coefficients for $b_{1}$ $(p<0.001)$ and $b_{4}(p<0.05)$. The constraints imposed by the disconfirmation model and the ideal point models were rejected for both ease of use $\left(F_{1,633}=102.23\right.$ for disconfirmation; $F_{4,633}=93.96$ for ideal point, both $p<0.001)$ and usefulness $\left(F_{1,631}=148.88\right.$ for disconfirmation; $F_{4,631}=102.28$ for ideal point, both $p<0.001$ ). There were no constraints to be tested for the experiences only model. However, the positive, significant coefficient for only $b_{1}$ (experience) with respect to ease of use is consistent with the experiences only model. The higher-order terms were not found to explain significantly additional variance for either ease of use $\left(F_{4,629}=1.588\right.$, n.s. $)$ or usefulness $\left(F_{4,627}=1.357\right.$, n.s. $)$. In sum, while the first and fourth conditions of the confirmatory approach were satisfied for both ease of use and usefulness, the second

Table 2

Descriptive statistics, reliability estimates, and correlations

\begin{tabular}{|c|c|c|c|c|c|c|c|}
\hline & $\alpha$ & $M$ & $S D$ & 1 & 2 & 3 & 4 \\
\hline \multicolumn{8}{|l|}{ Expectations } \\
\hline 1. Ease of Use & 0.87 & 5.39 & 1.17 & & & & \\
\hline 2. Usefulness & 0.93 & 5.59 & 1.26 & 0.49 & & & \\
\hline \multicolumn{8}{|l|}{ Experiences } \\
\hline 3. Ease of use & 0.84 & 4.94 & 1.27 & 0.21 & 0.37 & & \\
\hline 4. Usefulness & 0.93 & 4.85 & 1.54 & 0.21 & 0.22 & 0.56 & \\
\hline \multicolumn{8}{|l|}{ Dependent variable } \\
\hline 5. Satisfaction & 0.90 & 5.39 & 1.05 & 0.22 & 0.26 & 0.63 & 0.66 \\
\hline
\end{tabular}

Notes. $N=648$. All correlations were statistically significant, at least at $p<.01$. 
A Ease of Use

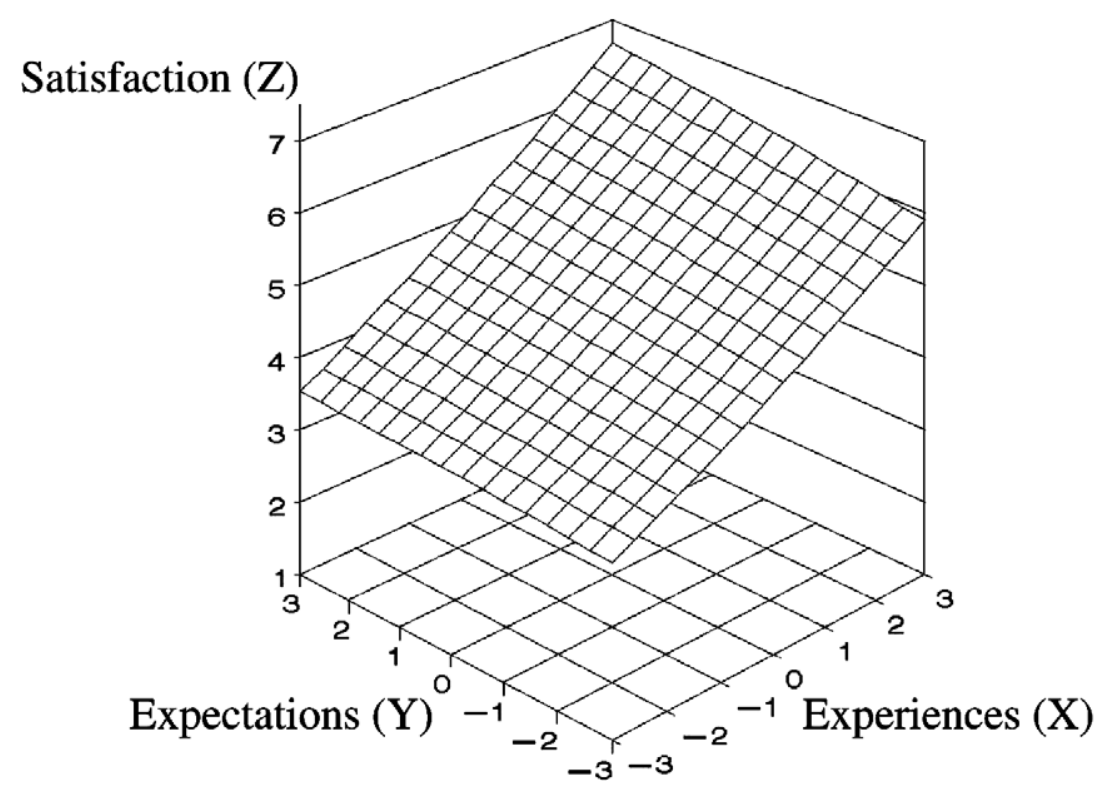

B Usefulness

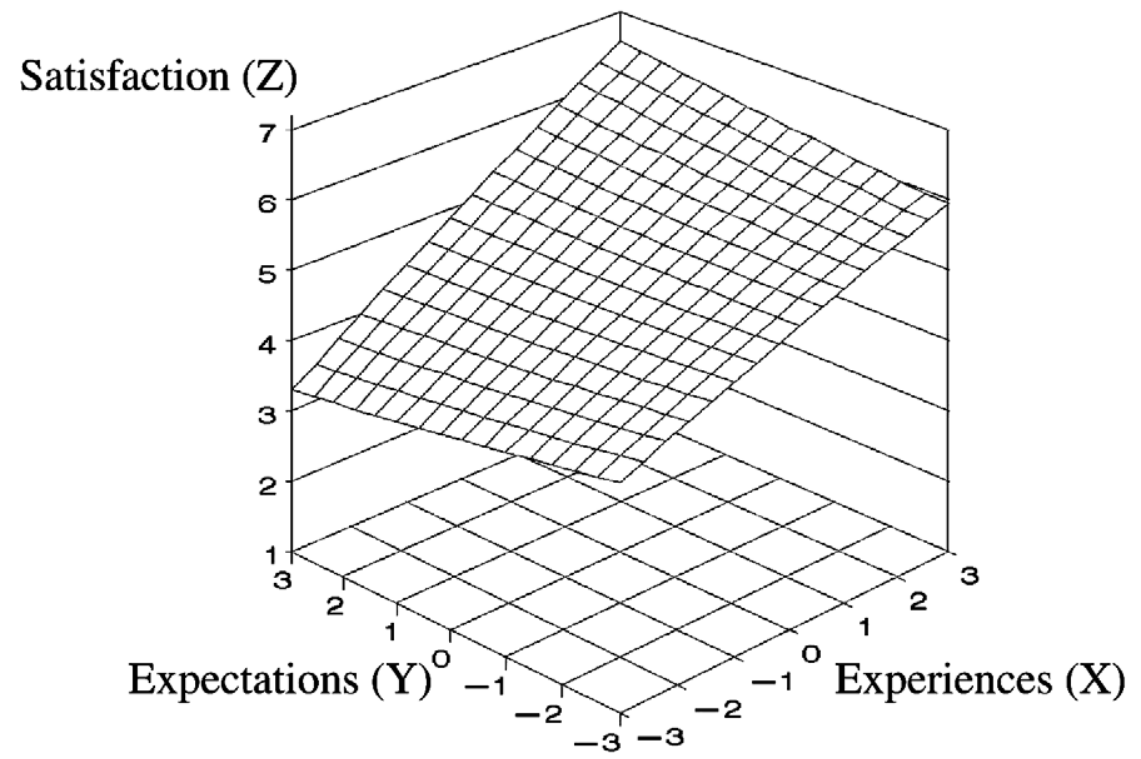

Fig. 2. (A and B) Response surface representations of empirical results.

and third were not. When all three quadratic terms are significant, response surface analysis is useful for interpreting the results (Edwards \& Parry, 1993). In this case, given that the higher-order terms were not significant, response surface analysis provides no additional benefit in interpreting the results.

\section{Discussion}

The paper discussed the theoretical underpinnings and propositions, response surfaces, and empirical tests and associated comparison of three different theoretical models that describe the combined effects of expectations and experiences in determining a key outcome - satisfaction-in the domain of a new information system implementation. We reviewed three models-disconfirmation, ideal point, and experiences only - and for the first time represented them in three-dimensional space to capture the nuances of the models' complex, curvilinear propositions. We conducted an empirical comparison of the different models using polynomial regression analysis, thus remedying critical methodological and analytical shortcomings in prior met expectations research. The results from the current work examining expectations and experiences using ease of use and usefulness as predictors of 
system satisfaction did not provide clear support for the disconfirmation or ideal point models. However, based on the observed pattern of results, the results for ease of use support an experiences only model while the results for usefulness support a modified version of the experiences only model.

The equal role of expectations and experiences suggested by both the disconfirmation and ideal point models was not evident. The pattern of coefficients from the analysis did not match the pattern suggested by either of these models and the constraints were also rejected. The entirely nonexistent role of expectations suggested by the experiences only model was supported for ease of use. The relationship between expectations and satisfaction for ease of use and usefulness was not significant, while the relationship between the interaction term and satisfaction for usefulness $(p<0.05)$ was significant. Thus, expectations do not play a role in influencing satisfaction with respect to ease of use, while expectations do play a weak moderating role in influencing satisfaction with respect to usefulness.

The moderating role of expectations found in the usefulness model suggests a modified experiences only model. When expectations are low and experiences are high, individuals may adjust their satisfaction evaluation downward towards their expectations, thus enacting a dissonance reduction strategy (see Festinger, 1962). The result leads them to have lowered satisfaction levels because their ultimate evaluation is influenced by their preconceived expectations. Similarly, when expectations are high and experiences are low, individuals may adjust their satisfaction evaluations upward towards their expectations. In this case, the positive effect of experiences is actually enhanced by positive expectations, such that when individuals have positive expectations and positive experiences their satisfaction is highest.

An important finding in this study is that the overall influence of expectations appears to be much less than suggested in some prior research (e.g., Ginzberg, 1981; Szajna \& Scamell, 1993). While the strong role of expectations in determining satisfaction is conceptually appealing, the flawed empirical techniques associated with difference scores discussed earlier may have led to the view that there is a substantial role for expectations while in reality, expectations have only a marginal influence on satisfaction. The overemphasis of expectations in determining satisfaction has similarly been identified by Irving and Meyer (1999) in the context of realistic job previews. The impact of this overemphasis of expectations in that context may have led to an overemphasis of the importance of realistic job previews as a management tool for expectation management (Irving \& Meyer, 1999). Similarly in this case, prior research may have overemphasized the importance of expectations when implementing information systems (Ginzberg, 1981; Staples et al., 2002; Szajna \& Scamell, 1993).
Although the higher-order terms of the model were not significant, it was still important to use polynomial regression and response surface methodology to understand the relationship among expectations, experiences, and satisfaction in this research. Translating the theoretical propositions of two of the three models into response surfaces and examining the empirical support for these models using confirmatory procedures of polynomial regression analyses enabled us to identify a disconnect between existing theoretical perspectives and the empirical reality. The use of a linear model in our study would suggest similar impacts of experiences and expectations, regardless of whether expectations exceeded experiences or vice versa. Yet, through polynomial modeling, we were able to identify different patterns depending on the relationship between expectations and experiences. In addition, measuring each component separately indicated that expectations had a much weaker influence on satisfaction when compared with experiences. In sum, our analysis suggested that empirical support for existing theories and the emphasis on the role of expectations as an important construct may have been an artifact of problems with analysis and measurement (see Edwards, 1994; Edwards \& Parry, 1993). While a number of studies have demonstrated the appropriateness of polynomial models in a variety of contexts (e.g., Antonioni \& Park, 2001; Edwards, 1994; Edwards \& Harrison, 1993; Edwards \& Parry, 1993; Edwards \& Rothbard, 1999; KristofBrown \& Stevens, 2001), the findings here serve as a continuing call to re-examine other organizational phenomena relying on congruence relationships with polynomial models.

A domain or context of study is an essential aspect of studying individuals' expectations and experiences and their influence on outcomes. The focus on a specific domain comes with limitations and strengths. It is possible that the findings may be specific to the context studied here, thus calling for future work to examine the potential generalizability of these findings. However, this limitation is not unique to the current work and is characteristic of most work in the met expectations stream (e.g., Irving \& Meyer, 1994; McKinney et al., 2002; Parasuraman, Zeithaml, \& Berry, 1994) and is typical of much work studying human behaviors that explicitly takes into account contextual influences (Klein, Dansereau, \& Hall, 1994). As noted earlier, the strengths of the context studied here tie to the extent to which information systems investments have grown and continue to grow in organizations but the failure rate is still alarmingly high (see Davis \& Venkatesh, 2004). An overwhelming number of these failures are not due to technical flaws but rather due to potential users rejecting the systems (Davis \& Venkatesh, 2004; Venkatesh et al., 2003). However, the results of this study call into question a previously held assumption 
that failure to meet expectations is an essential reason for system failure (e.g., Staples et al., 2002). Appreciating the more complex interplay between expectations and experiences provides opportunities to influence the ultimate success of information systems deployment in organizations.

Given that this is one of the first efforts to compare these models, especially using appropriate analytical techniques that can fully test the models, there are important future research directions worth considering in order to identify critical contingencies. Identifying appropriate contingencies is critical before drawing conclusions regarding the superiority of one model or another. In our study, individual differences were not explicitly modeled. It is possible that different types of individuals-i.e., different personality profiles - could react very differently and better fit one type of model or another. For example, it is possible that more conscientious individuals may respond in ways consistent with a particular model, while less conscientious individuals may respond in ways consistent with a different model. Alternatively, those who are high vs. low on performance goal orientation or learning goal orientation could fit different models. Kopalle and Lehmann (2001) provided evidence that disconfirmation sensitivity and perfectionism are important individual characteristics that alter the relationship between expectations and satisfaction evaluations. Also, in our study, employees' specific levels of fit with their job or organization were not modeled. Once again, it is possible that an employee's fit with his or her job may influence the response to new information systems and the appropriate model for predicting satisfaction. Thus, this work opens up important and interesting directions for future work that could integrate these findings with important streams of research in organizational behavior to further our understanding of expectation confirmation.

\section{Conclusions}

This research examined the relationship among expectations, experiences, and satisfaction. In addition to reviewing the central tenets of three different expectation confirmation models-i.e., disconfirmation, ideal point, and expectations only-the current work presented graphical and analytical representations of the models and tested the complex models of expectation confirmation using confirmatory procedures of polynomial regression analyses. No support was found for the disconfirmation or ideal point models. The results supported an experiences only model for ease of use and a modified experiences only model for usefulness. This work thus provides key insights into the role of expectations and experiences in the formation of satisfaction both in general and in the important context of information systems implementations.

\section{Acknowledgments}

We appreciate the many comments and suggestions provided by the Editor, Professor Jeffrey Edwards, throughout the review process of this paper. We are also thankful for the valuable comments of the anonymous reviewers. We appreciate the time and effort of Professor Ian Williamson, University of Maryland, Professor Dan Ganster, University of Arkansas, and Sandeep Goyal, University of Arkansas for reading and providing comments on different versions of this manuscript. Finally, we would like to thank Mitzi Montoya-Weiss for her contributions to the data collection and input to earlier versions of the paper.

\section{Appendix}

All items were measured using a 7-point Likert scale with the endpoints strongly disagree to strongly agree, unless noted otherwise.

Expectation items

Usefulness

I expect that CBS will enable me to accomplish tasks more quickly.

I expect that CBS will improve the quality of the work I do.

I expect that CBS will make it easier to do my job.

I expect that CBS will enhance my effectiveness on the job.

I expect that CBS will give me greater control over my job.

I expect that CBS will improve my productivity.

\section{Ease of use}

I expect that it will be easy to get CBS to do what I want it to do.

I expect that overall, CBS will be easy to use.

I expect that learning to operate CBS will be easy for me.

I expect that interacting with CBS will not require a lot of my mental effort.

\section{Experience items \\ Usefulness}

CBS enables me to accomplish tasks more quickly.

CBS improves the quality of the work I do.

CBS makes it easier to do my job.

CBS enhances my effectiveness on the job.

CBS gives me greater control over my job.

CBS improves my productivity.

\section{Ease of use}

It is easy to get CBS to do what I want it to do.

Overall, CBS is easy to use.

Learning to operate CBS is easy for me. 
Interacting with CBS does not require a lot of my mental effort.

\section{Satisfaction}

I am an enthusiastic user of CBS.

All things considered, my continuing to use CBS in my job is... (Extremely Negative to Extremely Positive).

All things considered, my continuing to use CBS in my job is... (Extremely Bad to Extremely Good)

All things considered, my continuing to use CBS in my job is... (Extremely Harmful to Extremely Beneficial).

\section{References}

Aiken, L. S., \& West, S. G. (1991). Multiple regression: Testing and interpreting interactions. Newbury Park, CA: Sage.

Anderson, J., \& Gerbing, D. (1988). Structural modeling in practice: A review and recommended two-step approach. Psychological Bulletin, 103, 411-423.

Anderson, R. E. (1973). Consumer dissatisfaction: The effect of disconfirmed expectancy on perceived product performance. Journal of Marketing Research, 10, 38-44.

Antonioni, D., \& Park, H. (2001). The effects of personality similarity on peer ratings of contextual work behaviors. Personnel Psychology, 54, 331-360.

Atwater, L. E., Ostroff, C., Yammarino, F. J., \& Fleenor, J. W. (1998). Self-other agreement: Does it really matter?. Personnel Psychology 51, 577-598.

Bailey, J. E., \& Pearson, S. W. (1983). Development of a tool for measuring and analyzing computer user satisfaction. Management Science, 29, 530-545.

Bandura, A. (1986). Social foundations of thought and action: A social cognitive theory. Englewood Cliffs, NJ: Prentice-Hall.

Belsley, D. A., Kuh, E., \& Welsch, R. E. (1980). Research diagnostics: Identifying influential data and sources of collinearity. New York: Wiley.

Bhattacherjee, A. (2001). Understanding information systems continuance: An expectation-confirmation model. MIS Quarterly, 25, 351-370.

Bhattacherjee, A., \& Premkumar, G. (2004). Understanding changes in belief and attitude toward information technology usage: A theoretical model and longitudinal test. MIS Quarterly, 28, 229-254.

Bollen, K. A., \& Jackman, R. W. (1990). Regression diagnostics: An expository treatment of outliers and influential cases. In J. Fox \& J. S. Long (Eds.), Modern methods of data analysis. Newbury Park, CA: Sage.

Brown, S. A., Massey, A. P., Montoya-Weiss, M., \& Burkman, J. R. (2002). Do I really have to? User acceptance of mandated technology. European Journal of Information Systems, 11, 283-295.

Buckley, M. R., Fedor, D. B., Veres, J. G., Wiese, D. S., \& Carraher, S. M. (1998). Investigating newcomer expectations and job-related outcomes. Journal of Applied Psychology, 83, 452-461.

Cadotte, E. R., Woodruff, R. B., \& Jenkins, R. L. (1987). Expectations and norms in models of consumer satisfaction. Journal of Marketing Research, 26, 305-314.

Christensen-Szalanski, J. J. J., \& Willham, C. F. (1991). The hindsight bias: A meta-analysis. Organizational Behavior and Human Decision Processes, 48, 147-168.
Churchill, G. A., Jr., \& Surprenant, C. (1982). An investigation into the determinants of customer satisfaction. Journal of Marketing Research, 19, 491-504.

Davis, F. D. (1989). Perceived usefulness, perceived ease of use, and user acceptance of information technology. MIS Quarterly, 13, 319-339.

Davis, F. D. (1993). User acceptance of information technology: System characteristics, user perceptions and behavioral impacts. International Journal of Man-Machine Studies, 38, 475-487.

Davis, F. D., Bagozzi, R. P., \& Warshaw, P. R. (1989). User acceptance of computer technology: A comparison of two theoretical models. Management Science, 35, 982-1002.

Davis, F. D., \& Venkatesh, V. (2004). Toward preprototype user acceptance testing of new information systems: Implications for software project management. IEEE Transactions on Engineering Management, 51(1), 31-46.

DeLone, W. H., \& McLean, E. R. (1992). Information systems success: The quest for the dependent variable. Information Systems Research, 3, 60-95.

DeLone, W. H., \& McLean, E. R. (2003). The DeLone and McLean model of information systems success: A ten-year update. Journal of Management Information Systems, 19, 9-30.

Devaraj, S., Fan, M., \& Kohli, R. (2002). Antecedents of B2C channel satisfaction and preference: Validating e-commerce metrics. Information Systems Research, 13, 316-333.

Dugoni, B. L., \& Ilgen, D. R. (1981). Realistic job previews and the adjustment of new employees. Academy of Management Journal, 24, 579-591.

Edwards, J. R. (1994). The study of congruence in organizational behavior research: Critique and a proposed alternative. Organizational Behavior and Human Decision Processes, 58, 51-100.

Edwards, J. R. (1995). Alternatives to difference scores as dependent variables in the study of congruence in organizational research. Organizational Behavior and Human Decision Processes, 64, 307-324.

Edwards, J. R. (1996). An examination of competing versions of the person-environment fit approach to stress. Academy of Management Journal, 39, 292-339.

Edwards, J. R. (2001). Alternatives to difference scores: Polynomial regression analysis and response surface methodology. In F. Drasgow \& N. W. Schmitt (Eds.), Advances in measurement and data analysis (pp. 350-400). San Francisco: Jossey-Bass.

Edwards, J. R. (2002). Alternatives to difference scores: Polynomial regression analysis and response surface methodology. In $\mathrm{F}$. Drasgow \& N. Schmidt (Eds.), Measuring and analyzing behavior in organizations: Advances in measurement and data analysis (pp. 350-400). San Francisco, CA: Jossey-Bass/Pfeiffer.

Edwards, J. R., \& Cooper, B. L. (1990). The person-environment fit approach to stress: Recurring problems and some suggested solutions. Journal of Organizational Behavior, 11, 293-307.

Edwards, J. R., \& Harrison, R. V. (1993). Job demands and worker health: Three-dimensional reexamination of the relationship between person-environment fit and strain. Journal of Applied Psychology, 78, 628-648.

Edwards, J. R., \& Parry, M. E. (1993). On the use of polynomial regression equations as an alternative to difference scores in organization research. Academy of Management Journal, 36, $1577-1613$.

Edwards, J. R., \& Rothbard, N. P. (1999). Work and family stress and well-being: An examination of person-environment fit in the work and family domains. Organizational Behavior and Human Decision Processes, 77, 85-129.

Fazio, R. H., \& Zanna, M. P. (1981). Direct experience and attitudebehavior consistency. New York: Academic Press.

Festinger, L. (1962). A theory of cognitive dissonance. Stanford: California: Stanford University Press. 
Fox, J. (1991). Regression diagnostics: An introduction. Newbury Park, CA: Sage.

Ginzberg, M. J. (1981). Early diagnosis of MIS implementation failure: Promising results and unanswered questions. Management Science, 27, 459-479.

Greenhaus, J. H., Seidel, C., \& Marinis, M. (1983). The impact of expectations and values on job attitudes. Organizational Behavior and Human Performance, 31, 394-417.

Harrison, D. A., Newman, D. A., \& Roth, P. L. (2006). How important are job attitudes? Meta-analytic comparisons of integrative behavioral outcomes and time sequences. Academy of Management Journal, 49, 305-325.

Hawkins, S. A., \& Hastie, R. (1990). Hindsight: Biased judgments of past events after the outcomes are known. Psychological Bulletin, 107, 311-327.

Hom, P. W., Griffeth, R. W., Palich, L. E., \& Bracker, J. S. (1999). Revisiting met expectations as a reason why realistic job previews work. Personnel Psychology, 52, 97-112.

Ilgen, D. R. (1971). Satisfaction with performance as a function of the initial level of expected performance and the deviation from expectations. Organizational Behavior and Human Performance, 6 , 345-361.

Irving, P. G., \& Meyer, J. P. (1994). Reexamination of the metexpectations hypothesis: A longitudinal analysis. Journal of Applied Psychology, 79, 937-949.

Irving, P. G., \& Meyer, J. P. (1995). On using direct measures of met expectations: A methodological note. Journal of Management, 21, $1159-1175$

Irving, P. G., \& Meyer, J. P. (1999). On using residual difference scores in the measurement of congruence: The case of met expectations research. Personnel Psychology, 52, 85-95.

Ives, B., Olson, M. H., \& Baroudi, J. J. (1983). The measurement of user information satisfaction. Communications of the ACM, 26, 785-793.

Jaccard, J., Wan, C. K., \& Turrisi, R. (1990). The detection and interpretation of interaction effects between continuous-variables in multiple-regression. Multivariate Behavioral Research, 25, 467-478.

Johnson, J. W., \& Ferstl, K. L. (1999). The effects of interrater and self-other agreement on performance improvement following upward feedback. Personnel Psychology, 52, 271-303.

Judge, T. A., Thoresen, C. J., Bono, J. E., \& Patton, G. K. (2001). The job satisfaction-job performance relationship: A qualitative and quantitative review. Psychological Bulletin, 127, 376-407.

Karahanna, E., Straub, D. W., \& Chervany, N. L. (1999). Information technology adoption across time: A cross-sectional comparison of pre-adoption and post-adoption beliefs. MIS Quarterly, 23, $183-213$.

Klein, J. G. (1999). Developing negatives: Expectancy assimilation and contrast in product judgments. Advances in Consumer Research, 26, 463-468.

Klein, K. J., Dansereau, F., \& Hall, R. J. (1994). Level issues in theory development, data collection, and analysis. Academy of Management Review, 19, 195-229.

Kopalle, P. K., \& Lehmann, D. R. (2001). Strategic management of expectations: The role of disconfirmation sensitivity and perfectionism. Journal of Marketing Research, 36, 386-394.

Kotter, J. P. (1973). The psychological contract: Managing the joining up process. California Management Review, 15, 91-93.

Kristof-Brown, A. L., \& Stevens, C. K. (2001). Goal congruence in project teams: Does the fit between members' personal mastery and performance goals matter? Journal of Applied Psychology, 86, 1083-1095.

Lambert, L. S., Edwards, J. E., \& Cable, D. M. (2003). Breach and fulfillment of the psychological contract: A comparison of traditional and expanded views. Personnel Psychology, 56, 895-934.
Lau, V. C. S., Au, W. T., \& Ho, J. M. C. (2003). A qualitative and quantitative review of antecedents of counterproductive behavior in organizations. Journal of Business \& Psychology, 18, 73-99.

Lawrence, M., \& Low, G. (1993). Exploring individual user satisfaction within user-led development. MIS Quarterly, 17, 195-208.

Lee, T. W., Ashford, S. J., Walsh, J. P., \& Mowday, R. T. (1992). Commitment propensity, organizational commitment, and voluntary turnover: A longitudinal-study of organizational entry processes. Journal of Management, 18, 15-32.

Lee, T. W., \& Mowday, R. T. (1987). Voluntarily leaving an organization: An empirical investigation of Steers and Mowday's model of turnover. Academy of Management Journal, 30, 721-743.

Lyytinen, K. (1988). Expectation failure concept and systems analysts' view of information system failures: Results of an exploratory study. Information \& Management, 14, 45-56.

Major, D. A., Kozlowski, S. W. J., Chao, G. T., \& Gardner, P. D. (1995). A longitudinal investigation of newcomer expectations, early socialization outcomes, and the moderating effects of role development factors. Journal of Applied Psychology, 80, 418.

Markus, M. L., \& Benjamin, R. I. (1997). The magic bullet theory in it-enabled transformation. Sloan Management Review, 38, 55-68.

Mathieson, K. (1991). Predicting user intentions: Comparing the technology acceptance model with the theory of planned behavior. Information Systems Research, 2, 173-191.

McElroy, J. C., Morrow, P. C., \& Mullen, E. J. (1996). Intraorganizational mobility and work related attitudes. Journal of Organizational Behavior, 17, 363-374.

McKinney, V., Yoon, K., \& Zahedi, F. (2002). The measurement of web-customer satisfaction: An expectation and disconfirmation approach. Information Systems Research, 13, 296-315.

Mellers, B. A., Schwartz, A., Ho, K., \& Ritov, I. (1997). Decision affect theory: How we feel about risky options. Psychological Science, 8, 423-429.

Melone, N. P. (1990). A theoretical assessment of the user-satisfaction construct in information systems research. Management Science, 36, 76-91.

Moon, J. W., \& Kim, Y. G. (2001). Extending the tam for a worldwide-web context. Information \& Management, 38, 217-230.

Oliver, R. L. (1976). Hedonic reactions to the disconfirmation of product performance expectations: Some moderating conditions. Journal of Applied Psychology, 61, 246-250.

Oliver, R. L. (1977). Effect of expectation and disconfirmation on postexposure product evaluations: An alternative interpretation. Journal of Applied Psychology, 62, 480-486.

Olson, J. C., \& Dover, P. A. (1979). Disconfirmation of consumer expectations through product trial. Journal of Applied Psychology, 64, 179-189.

Parasuraman, A., Zeithaml, V. A., \& Berry, L. L. (1994). Reassessment of expectations as a comparison standard in measuring service quality: Implications for further research. Journal of Marketing, 58, 111-124.

Patterson, P. G. (1993). Expectations and product performance as determinants of satisfaction for a high-involvement purchase. Psychology \& Marketing, 10, 449-465.

Peter, J. P., Churchill, G. A., Jr., \& Brown, T. J. (1993). Caution in the use of difference scores in consumer research. Journal of Consumer Research, 19, 655-662.

Phillips, J. M. (1998). Effects of realistic job previews on multiple organizational outcomes: A meta-analysis. Academy of Management Journal, 41, 673-690.

Pinsonneault, A., \& Kraemer, K. L. (1997). Middle management downsizing: An empirical investigation of the impact of information technology. Management Science, 43, 659-679.

Pinsonneault, A., \& Rivard, S. (1998). Information technology and the nature of managerial work: From the productivity paradox to the Icarus paradox. MIS Quarterly, 22, 287-311. 
Pitt, L. F., Watson, R. T., \& Kavan, C. B. (1997). Measuring information systems service quality: Concerns for a complete canvas. MIS Quarterly, 21, 209-221.

Porter, L. W., \& Steers, R. M. (1973). Organizational, work, and personal factors in employee turnover and absenteeism. Psychological Bulletin, 80, 151-176.

Prakash, V. (1984). Validity and reliability of the confirmation of expectations paradigm as a determinant of consumer satisfaction. Journal of the Academy of Marketing Science, 12, 63-76.

Premack, S. L., \& Wanous, J. P. (1985). A meta-analysis of realistic job preview experiments. Journal of Applied Psychology, 10, 706-719.

Robinson, S. L. (1996). Trust and breach of the psychological contract. Administrative Science Quarterly, 41, 574-599.

Saks, A. M. (1994). A psychological process investigation for the effects of recruitment source and organization information on job survival. Journal of Organizational Behavior, 15, 225-244.

Seddon, P. B. (1997). A respecification and extension of the DeLone and McLean model of IS success. Information Systems Research, 8, 240-253.

Sherif, M., \& Hovland, C. I. (1961). Social judgment: Assimilation and contrast effects in communication and attitude change. New Haven: Yale University Press.

Staples, D. S., Wong, I., \& Seddon, P. B. (2002). Having expectations of information systems benefits that match received benefits: Does it really matter? Information \& Management, 40, 115-131.

Suszko, M. K., \& Breaugh, J. A. (1986). The effects of realistic job previews on applicant self-selection and employee turnover, satisfaction, and coping ability. Journal of Management, 12, 513-523.

Sutton, G., \& Griffin, M. A. (2004). Integrating expectations, experiences, and psychological contract violations: A longitudinal study of new professionals. Journal of Occupational and Organizational Psychology, 77, 493-514.

Szajna, B., \& Scamell, R. W. (1993). The effects of information system user expectations on their performance and perceptions. MIS Quarterly, 23, 493-516.

Tannebaum, S. I., Mathieu, J. E., Salas, E., \& Cannon-Bowers, J. A. (1991). Meeting trainees' expectations: The influence of training fulfillment on the development of commitment, self-efficacy, and motivation. Journal of Applied Psychology, 76, 759-769.

Taylor, S., \& Todd, P. A. (1995). Understanding information technology usage: A test of competing models. Information Systems Research, 6, 144-176.
Turnley, W. H., \& Feldman, D. C. (2000). Re-examining the effects of psychological contract violations: Unmet expectations and job dissatisfaction as mediators. Journal of Organizational Behavior, 21, 25-42.

Tversky, A., \& Kahneman, D. (1974). Judgment under uncertainty: Heuristics and biases. Science, 185, 1124-1131.

Van Maanen, J. (1975). Police socialization: A longitudinal examination of job attitudes in an urban police department. Administrative Science Quarterly, 20, 206-228.

Van Vianen, A. E. M. (2000). Person-organization fit: The match between newcomers' and recruiters' preferences for organizational cultures. Personnel Psychology, 53, 113-149.

Venkatesh, V., \& Davis, F. D. (2000). A theoretical extension of the technology acceptance model: Four longitudinal field studies. Management Science, 46, 186-204.

Venkatesh, V., Morris, M. G., Davis, G. B., \& Davis, F. D. (2003). User acceptance of information technology: Toward a unified view. MIS Quarterly, 27, 425-478.

Venkatraman, N., \& Prescott, J. E. (1990). Environment-strategy coalignment: An empirical test of its performance implications. Strategic Management Journal, 11, 1-23.

Wanous, J. P. (1980). Organizational entry: Recruitment, select, orientation, and socialization of newcomers. Reading, MA: Addison-Wesley.

Wanous, J. P. (1992). Organizational entry: Recruitment, selection, orientation, and socialization of newcomers ( $2 \mathrm{nd}$ ed.). Reading, MA: Addison-Wesley.

Wanous, J. P., Poland, T. D., Premack, S. L., \& Davis, K. S. (1992) The effects of met expectations on newcomer attitudes and behaviors: A review and meta-analysis. Journal of Applied Psychology, 77, 288-297.

Weaver, D., \& Brickman, P. (1974). Expectancy, feedback, and disconfirmation as independent factors in outcome satisfaction. Journal of Personality and Social Psychology, 30, 420-428.

Yi, Y. (1990). A critical review of consumer satisfaction. In V. A. Zeithaml (Ed.), Review of marketing (pp. 68-123). Chicago: American Marketing Association.

Yoon, Y., \& Guimaraes, T. (1995). Assessing expert systems: Impact on users' jobs. Journal of Management Information Systems, 12, 225-249.

Zmud, R. W. (1980). Management of large software development efforts. MIS Quarterly, 4, 45-56. 